\title{
Para além de vínculos diretos entre características fonético-segmentais e ortográficas na escrita infantil
}

\author{
Beyond strict links between phonetic-segmental \\ and orthographic aspects in writing acquisition
}

Lourenço Chacon
UNESP

\begin{abstract}
We searched for arguments against the current and common idea that only phonetic segmental aspects of speech are taken in account by children in their orthographic hypothesis. By analyzing syllabic coda occurrences in written texts produced by 5-6 years old children, we detected contribution of prosodic, morphologic, enunciative and discursive aspects of language in those occurrences. We attributed these various types of contribution to various ways of children/ language relationship.
\end{abstract}

Keywords

Orthography; Writing acquisition; Syllabic coda.

\section{Resumo}

Questionando o olhar que freqüentemente estabelece vínculos diretos entre características fonético-segmentais possíveis em enunciados falados e características ortográficas na escrita infantil, buscamos outras características da língua e da linguagem que contribuiriam para o estabelecimento desses vínculos. Para tanto, analisamos registros de coda silábica em textos escritos de crianças entre 5 e 6 
anos de uma escola municipal de educação infantil. Nesses registros, observamos, para além desses vínculos diretos, a contribuição de aspectos da língua e da linguagem como os prosódicos, morfológicos, enunciativos e discursivos. Atribuímos a contribuição desses aspectos para o registro da coda às várias formas como se mostram na escrita inicial as relações entre a criança e a linguagem.

\section{Palavras-chave}

Convenções ortográficas; Aquisição da escrita; Coda silábica. 


\section{Introdução}

É

quase consensual, sobretudo entre profissionais que se ocupam da prática da alfabetização (como pedagogos, psicopedagogos e fonoaudiólogos),

que as crianças, nos momentos iniciais de seu aprendizado formal da escrita, tentariam plasmar, nos caracteres ortográficos de seus enunciados escritos, características fonético-segmentais que detectariam em enunciados falados.

Obviamente, não se trata de negar que as crianças estabeleçam esse tipo de vínculo em sua escrita inicial. Com efeito, antes de iniciarem seu aprendizado formal da escrita (em escolas de educação infantil e/ou em escolas de ensino fundamental), elas já participam de múltiplas práticas de oralidade. E certamente procuram se ancorar em características fonético-segmentais dessas práticas relacionando-as aos caracteres ortográficos com os quais passam a ter (mais) contato em práticas de letramento desenvolvidas em contexto escolar. Mas parece haver outras características da língua e da linguagem que contribuem para o estabelecimento desses vínculos na chamada aquisição da escrita especialmente numa posição silábica de aquisição mais tardia na escrita infantil: a da coda. A localização dessas outras características é o objetivo do presente trabalho.

\section{Aspectos metodológicos}

Os dados sobre os quais nos debruçaremos foram extraídos de 120 textos produzidos em contexto escolar por crianças de pré-escola em nível III, de uma Escola Municipal do Ensino Infantil (EMEI) da cidade de Marília (SP). Essa escola localiza-se em bairro considerado, em termos socioeconômicos, como de classe baixa - a renda familiar da grande maioria da clientela escolar não excede dois salários mínimos. Quanto ao contexto de produção dos textos, foram produzidos para avaliação (feita pela Secretaria Municipal de Educação) do nível de alfabetização das crianças de toda a Rede de Ensino. 
Os 120 textos foram produzidos com base em seis diferentes propostas temáticas nos meses de fevereiro, março, abril, maio, agosto e setembro de 2005. Seus escreventes foram 20 crianças ( 10 do gênero feminino e 10 do gênero masculino) com faixa etária entre cinco e seis anos. Trata-se de propostas que não permitiam uma escrita mais particular a cada criança (por exemplo, falar das coisas que mais a agradaram numa festa junina, como ocorreu no mês de junho), já que as particularidades nos dificultariam uma verificação de tendências mais recorrentes nos dados. Para efeito de melhor comparação, foram selecionados textos nos quais as 20 crianças escreveram, por exemplo, uma mesma quadrinha ou uma mesma canção infantil. O critério principal de inclusão dos textos de uma criança na amostra foi sua freqüência em mais de $85 \%$ das aulas durante todo o período escolar.

Buscamos, em cada proposta, todas as palavras que apresentavam a chamada coda silábica. ${ }^{1}$ Nas seis propostas que selecionamos, identificamos 21 palavras, com 24 possibilidades de coda simples, já que duas palavras repetiramse no corpus (gosta e motorista) e uma terceira apresentou duas codas (aNdaR).

A Tabela 1 mostra a relação dessas palavras:

TABELA 1

Distribuição das palavras e dos tipos de coda em função das propostas

\begin{tabular}{|c|c|c|c|c|c|}
\hline \multirow[t]{2}{*}{ Propostas } & \multicolumn{4}{|c|}{ Tipos de coda } & \multirow[t]{2}{*}{ Palavras } \\
\hline & Fricativa & Vibrante & Nasal & Glide & \\
\hline $\mathrm{P} 1$ & 1 & 2 & & & lápiS; cadeRno. aRmário \\
\hline $\mathrm{P} 2$ & & & 2 & & moraNgo; laraNja \\
\hline $\mathrm{P} 3$ & 2 & & 1 & 2 & bateU; goSta; miM; goSta; eU \\
\hline $\mathrm{P} 4$ & & 2 & 1 & & seNta; aR; paraR \\
\hline P5 & 4 & 1 & 2 & & $\begin{array}{l}\text { motoriSta; motoriSta; aNdaR; } \\
\text { pelaS; ruaS; ateNção }\end{array}$ \\
\hline P6 & 1 & 2 & 1 & & $\begin{array}{l}\text { ceRcadinha; eStá; demoraNdo; } \\
\text { ceRteza }\end{array}$ \\
\hline
\end{tabular}

Chegamos, assim, a um total de 480 possibilidades ( 24 possibilidades nas propostas x 20 sujeitos) de ocorrência de coda para o conjunto de todos os nossos sujeitos. 
Consideramos como registro de coda, ou seja, o que chamamos de ocorrência de coda, qualquer registro ortográfico que mantivesse correspondência fonológica com as possibilidades de coda simples do Português Brasileiro (PB). Traduzindo como coda, de acordo com o modelo de Selkirk (1982), o que Camara Jr. (1975) postula como possibilidades de travamento silábico do PB, chegaríamos a cinco possibilidades de coda em nossos dados, já que, para esse autor:

(...) há 4 modalidades de sílaba travada em português: V/z/, V/r/, V/l/, que desaparece com a vocalização do /l/ para /w/, e V/y,w/ (ditongos decrescentes).

Pode-se acrescentar um quinto tipo, V/N/, com a interpretação da chamada 'vogal nasal', em português, como sendo fonologicamente 'vogal fechada por consoante nasal'. (...) Em outros têrmos, é um arquifonema dos fonemas nasais existentes em português, que deles só conserva o traço comum da nasalidade. (CAMARAJr., 1975, p. 30).

No entanto, como, na variedade lingüística de nossos sujeitos, a coda lateral "desaparece com a vocalização do /1/ para /w/" e como, além desse desaparecimento, não houve nenhuma ocorrência, em nossos dados, de palavra cuja ortografia remetesse a esse tipo de coda (como poderia ser o caso, por exemplo, de uma palavra como "volta"), deixamos de considerá-la como possibilidade. Também por ausência de possibilidade em nossos dados, o glide anterior /y/ não foi considerado. Chegamos, portanto, a quatro tipos de possibilidades de coda no material proposto como avaliação para as crianças: fricativa, vibrante, glide posterior e nasal. ${ }^{2}$ Estivemos, portanto, atentos a todas as marcas gráficas de coda nasal /N/, vibrante /R/ e fricativa /S/, bem como de glide /W/, este último no caso de não fazer parte de ditongos que variam com monotongos - como em ['kowru] / ['koru] ${ }^{3}$ - estando, ou não, essas marcas de acordo com as convenções ortográficas, desde que, no entanto, elas preservassem o valor fonológico de cada tipo de coda.

Assim, consideramos, para codas nasais, registros dos sujeitos, como: (1) o sinal gráfico til ( ), verificado, por exemplo, na palavra "laranja" grafada como "loãta"; e (2) a utilização do grafema "m", pelos sujeitos, mesmo quando, pelas convenções ortográficas, seria adequado o grafema "n", conforme ocorreu na sílaba "ran" palavra "morango" grafada como "ram". 
Para os glides, além do registro mais convencional "u", consideramos também o registro "o", quando este grafema correspondia ao glide posterior. É o que ocorreu, por exemplo, na palavra "eu", registrada como "eo".

Quanto às codas vibrante e fricativa, quando registradas, foram marcadas sempre por seus grafemas mais convencionais, ou seja, respectivamente, "r" e "s".

Vejamos exemplos das crianças que remetem a cada um dos tipos de coda verificados em nossos dados:

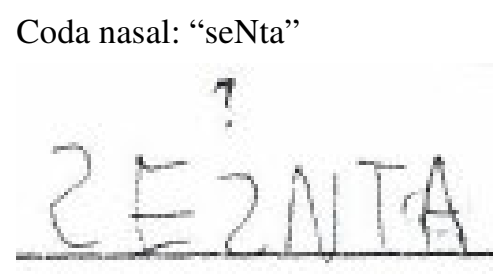

Coda semivogal: "bateU"

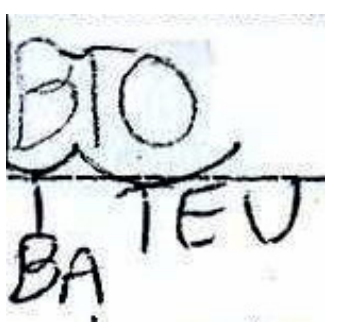

Coda vibrante: "ceRcadinha"
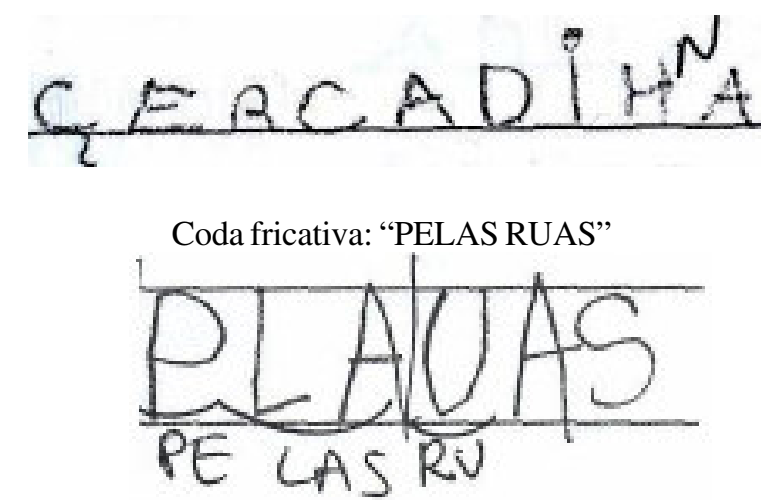

\section{Resultados}

Dentre os 120 textos selecionados da produção escrita das 20 crianças, conforme antecipamos, houve 480 possibilidades de registros de coda. Desse total de possibilidades, 129 (26,88\%) foram marcadas pelo conjunto das crianças, como mostra o Gráfico 1: 


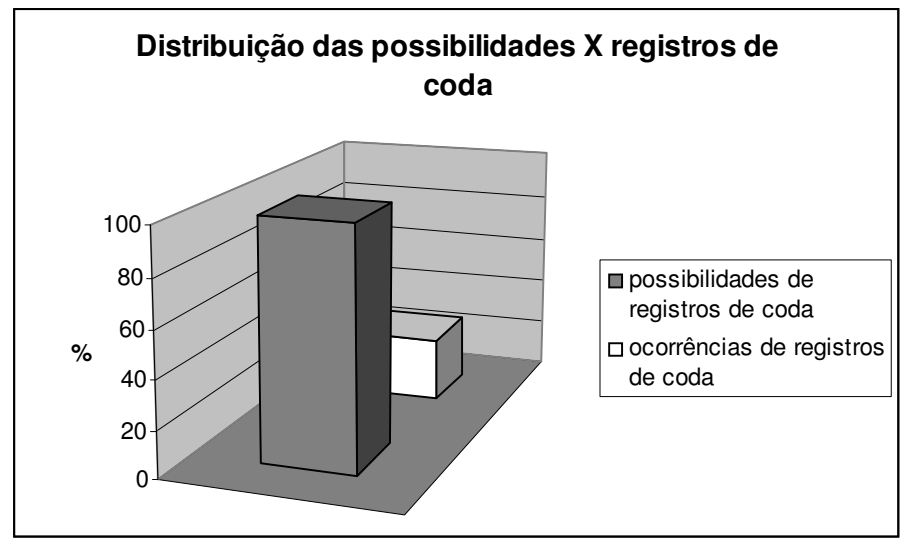

GRÁFICO 1: Distribuição das possibilidades X registros de codas pelas crianças

Não levantaremos, neste trabalho, razões para esse baixo percentual de ocorrências, já que: (1) o fizemos em trabalho anterior sobre os mesmos dados (CHACON); e (2) nosso objetivo aqui é localizar elementos da língua e da linguagem que contribuem para o estabelecimento de vínculos entre características fonético-segmentais e características ortográficas possivelmente em ação nessas ocorrências (independentemente de seu percentual).

Para alcançar nosso objetivo, inicialmente destacaremos duas tendências mais gerais nos registros de coda das crianças - na medida em que dizem respeito ao total, e não a tipos mais específicos, de registros de coda. Em seguida, destacaremos tendências que mais diretamente dizem respeito a um ou a outro tipo de registro de coda (nasal, fricativa, vibrante e semivogal posterior).

A primeira tendência geral foi a de que houve um aumento gradativo de registro de codas ao longo do ano - Proposta 1 (05); Proposta 2 (06); Proposta 3 (17); Proposta 4 (18); Proposta 5 (58); e Proposta 6 (47) -, como se pode visualizar no Gráfico 2: 


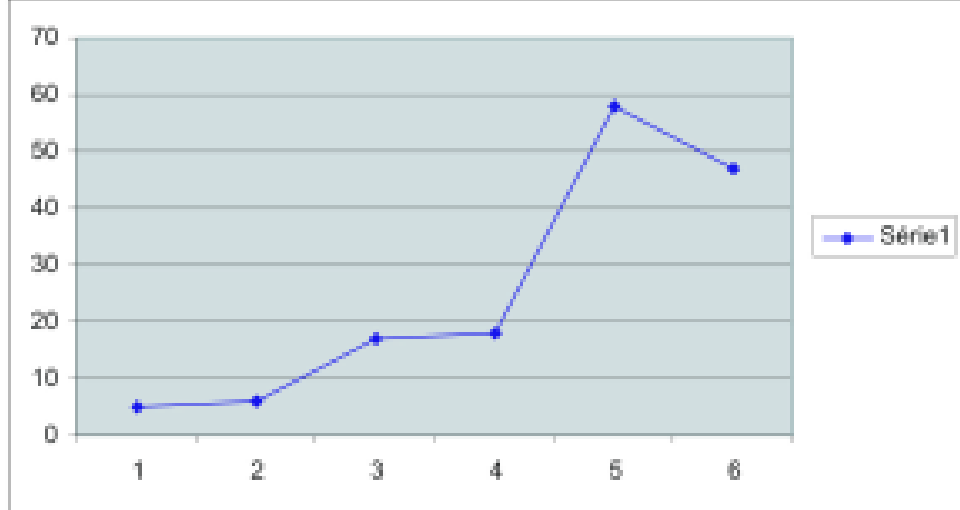

GRÁFICO 2: Registros de codas ao longo do ano

Esse resultado sugere que o maior tempo de inserção em práticas de letramento (dentre outros que exporemos a seguir) é um dos fatores que atua em favor do estabelecimento de vínculos entre características fonético-segmentais e características ortográficas no aprendizado formal da escrita. Essas práticas, sobretudo quando desenvolvidas em contexto escolar, tendem a favorecer a percepção (tanto auditiva, quanto visual) da posição da coda, levando, conseqüentemente, a um maior número de registros por parte das crianças.

Quanto à segunda tendência, verificamos que os registros identificados ou estão de acordo com as convenções ortográficas ou de acordo com diferentes possibilidades ortográficas para um mesmo tipo de coda - fato que, a nosso ver, (também) decorre da inserção das crianças em práticas de letramento, sobretudo aquelas desenvolvidas em contexto escolar. Assim, nasais foram registradas com M ou com N; semivogais posteriores, com O ou com U; fricativas, sempre com $\mathrm{S}$; vibrantes, sempre com R. Vejamos exemplos em que houve mais de uma possibilidade ortográfica de registro, situação ocorrida com registros de nasais e de semivogais posteriores: 
Exemplos de registros para coda nasal
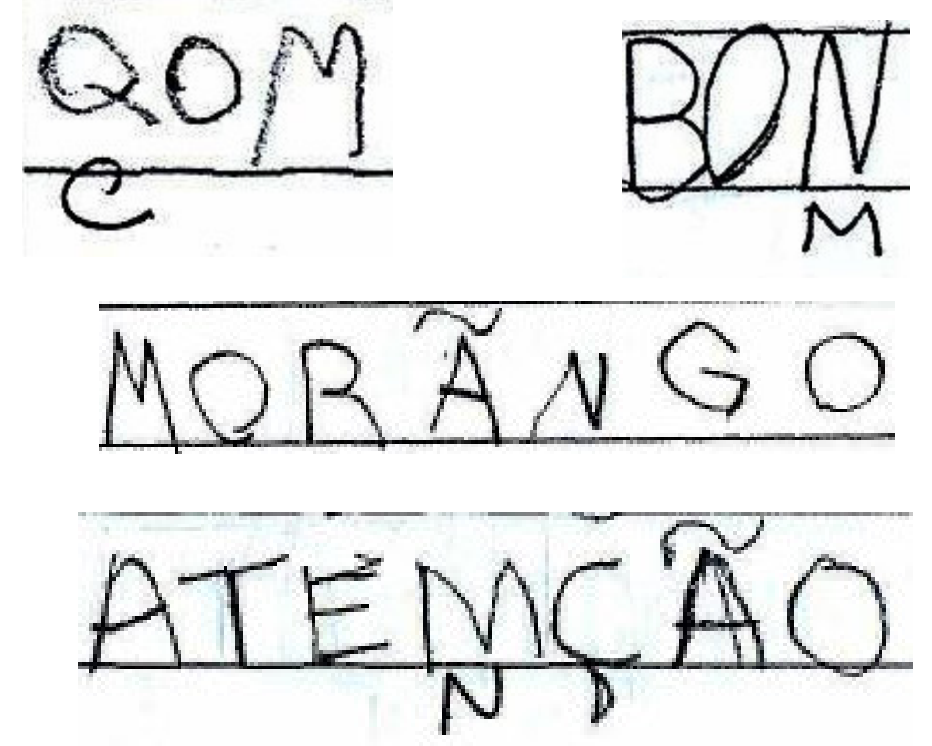

Exemplos de registros para coda semivogal:
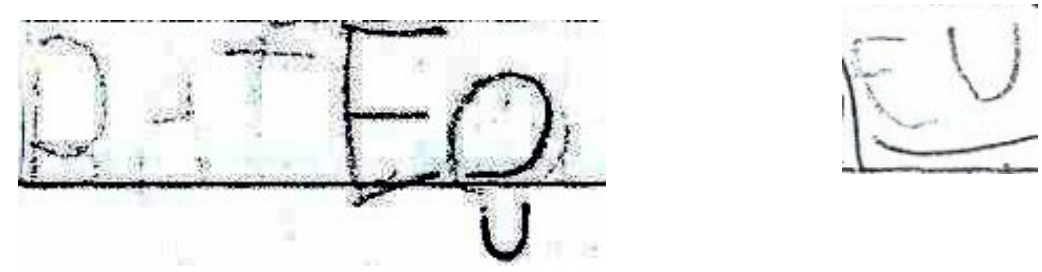

Pode-se verificar, nessas ocorrências, a integração que as crianças fazem entre, de um lado, características fonético-segmentais (como as de nasalização e de velarização) que certamente elas detectam em enunciados falados e, de outro lado, características ortográficas com as quais estão às voltas em seu processo de escolarização (mas, obviamente, não só nele). Conforme antecipamos, embora algumas marcas de coda não obedeçam às prescrições ortográficas, mesmo assim as crianças já fazem correspondências mais gerais entre esses dois tipos de características - o que confirma a contribuição que a inserção em práticas letradas tem para o estabelecimento de vínculos entre esses dois tipos de características no aprendizado formal da escrita. 
Mas outras características da língua e da linguagem (além da inserção em práticas de letramento) podem ser detectadas pelas crianças e levadas em conta nas conexões que fazem entre características fonético-segmentais e características ortográficas. Para tanto, vejamos tendências mais particulares aos registros de cada tipo de coda.

\subsection{Considerações sobre registros de coda nasal}

Em primeiro lugar, é de se destacar que $87,5 \%$ dos registros que envolveram a coda nasal estiveram corretos, mesmo quando a palavra não era integralmente escrita de acordo com as convenções ortográficas. Nos 12,5\% restantes, ou houve substituições de $\mathrm{M}$ para $\mathrm{N}$, ou de $\mathrm{N}$ para $\mathrm{M}$.

Observa-se, pois, que, para além de uma possível detecção de características fonéticas de nasalidade, houve sensibilidade das crianças para opções em concorrência no eixo paradigmático das possibilidades ortográficas da coda nasal ( ou M ou N). Houve, ainda, sensibilidade aos padrões de concatenação que envolvem a escrita da coda nasal, ou seja, M em final de palavra - única opção prevista para esse grafema no corpus; $\mathrm{N}$, antes dos demais grafemas, com exceção de $\mathrm{P}$ e de B, possibilidades inexistentes em nossos dados.

Assim, mais do que correspondências entre características fonéticas e características ortográficas, é a própria detecção dos dois princípios fundamentais de relações entre elementos lingüísticos que se mostra nessas ocorrências.

\subsection{Considerações sobre registros de coda fricativa}

Um primeiro grupo de palavras (presentes nas propostas 5 e 6 ) recebeu, de 10 diferentes sujeitos, um total de 31 registros de coda fricativa, distribuídos da seguinte maneira: pelas $=05 ;$ motorista $=06 ;$ ruas $=10 ;$ está $=10$.

Já um segundo grupo de palavras (presentes nas propostas 1 e 3) recebeu, de dois diferentes sujeitos, quatro registros, assim distribuídos: lápis $=2 ;$ gosta $=2$.

Confirmando tendência geral acima exposta, o tempo de inserção (maior/ menor) em práticas de letramento certamente contribuiu para essa distribuição, já que as palavras do primeiro grupo (que tiveram maior quantidade de registros, por maior número de sujeitos) ocorreram nas duas últimas propostas. $\mathrm{E}$ inversamente: as do segundo grupo (com menor quantidade de registros e de sujeitos) ocorreram na primeira e na terceira propostas. 
Mas outros fatos podem também ter contribuído para esses resultados. Um deles é a informação morfológica. Em pelas e em ruas, a marca de plural nominal parece ter incrementado o estabelecimento de conexões entre características fonético-segmentais e ortográficas da coda. Sobretudo porque, na variedade lingüística dos sujeitos, a coda fricativa, se falada nessas palavras, o seria preferencialmente no especificador "pelas" e raramente no substantivo "ruas".

Esse tipo de contribuição, a nosso ver, confirma resultados de Miranda (2008a) sobre a grafia de vogais átonas finais. Com efeito, ao detectar, na escrita de um grande número de estudantes do ensino fundamental, um percentual muito maior de grafias não-convencionais para a vogal anterior $(\mathrm{E})$, em relação à vogal posterior $(\mathrm{O}), \mathrm{a}$ autora observa:

Se pensássemos apenas na relação ortografia/fonética ou ortografia/ fonologia, ficaríamos sem resposta para esses resultados discrepantes. Isso porque, em termos fonético-fonológicos, temos uma neutralização no sistema, cuja conseqüência é a alternância entre vogais médias e altas nessa posição, sejam elas coronais ou labiais, e não haveria, portanto, motivos para tamanha diferença na performance das crianças no que diz respeito à grafia de 'o' e 'e' como mostram os resultados obtidos. (op. cit., p. 7).

A explicação que a autora fornece para essa discrepância vem ao encontro de nossos resultados: "Um possível modo de resposta pode estar relacionado ao fato de ser o 'o' átono final, um marcador de palavra, ou seja, um segmento portador de traços morfológicos (...)" (id. ibid.)

Mas, além da informação morfológica, que parece explicar alguns de nossos resultados com relação à coda fricativa, ainda sobre esse tipo de coda também a informação enunciativa e a prosódica podem ter sido um fator de incremento de conexões entre características fonético-segmentais e ortográficas. Com efeito, a palavra "motorista" é marca de um ato interpelativo (designa o alocutário do enunciado) no texto a ser escrito pelas crianças, ${ }^{4}$ condição na qual pode receber grande investimento prosódico, já que, por corresponder a uma frase entonacional (NESPOR; VOGEL, 1986), em situações de fala seria proferida com contorno entonacional característico e, muitas vezes, delimitado por pausas.

Vê-se, pois, que diferentes elementos da língua e da linguagem podem estar em ação nos vínculos entre características fonético-segmentais e características ortográficas da coda fricativa na escrita infantil. 


\subsection{Considerações sobre registros de coda vibrante}

Nos dados, um primeiro grupo de palavras (presentes na proposta 1) recebeu, de dois diferentes sujeitos, um total de 3 registros, assim distribuídos: caderno $=2 ;$ armário $=1$. Já um segundo grupo de palavras (presentes na proposta 6) recebeu, de dez diferentes sujeitos, um total de 17 registros, a saber: cercadinh $a=8 ;$ certez $a=9$. Por fim, um terceiro grupo de palavras (presentes nas propostas 4 e 5) recebeu, de nove diferentes sujeitos, um total de 23 registros, distribuídos da seguinte maneira: $\operatorname{ar}=6 ;$ parar $=8$; andar $=9$.

Novamente a tendência geral de um maior tempo de inserção em práticas de oralidade favorecer o aumento de registros é verificada: a menor quantidade de registros, nas palavras do primeiro grupo, ocorreu na primeira proposta; já a maior quantidade, no segundo grupo, ocorreu na última proposta.

Mas, semelhantemente ao que ocorreu com a coda fricativa, a informação morfológica também parece contribuir para o estabelecimento de conexões entre características fonético-segmentais e características ortográficas na escrita infantil. Em parar e andar, essa contribuição pode advir de o grafema R coincidir com a marca morfológica de infinitivo verbal. Reforça essa nossa interpretação o fato de, na variedade lingüística das crianças em estudo, a coda, nesses casos, raramente ocorrer em enunciados falados em situações coloquiais.

Além de características morfológicas, o próprio gênero discursivo também pode ter contribuído para o estabelecimento de conexões. Vejamos: as palavras em destaque fazem parte de uma quadrinha:

A boneca senta e chora

A pipa voa lá no ar

O pião gira e rebola

A bola rola sem parar.

Os pontos em que elas ocorrem nessa quadrinha as colocam em situação de rima; conseqüentemente, o aparecimento de uma delas cria a expectativa de retorno de parte de alguns de seus segmentos fonéticos (no caso -ar) em outro ponto metricamente previsível da quadrinha. Como as rimas se marcam pelo acento, a conjunção de características prosódicas que o tornam proeminente na fala (combinação entre aumento de duração, aumento de intensidade e aumento de freqüência $)^{5}$ também pode ter contribuído, nesse caso, para conexões entre características fonético-segmentais e características ortográficas. 
Semelhantemente ao que dissemos a respeito da coda fricativa, para além de um vínculo direto, é um conjunto de características que pode favorecer conexões entre elementos fonético-segmentais e ortográficos nos registros de coda vibrante na escrita infantil.

\subsection{Considerações sobre registros de coda semivocálica posterior}

As possibilidades (e ocorrências) desse tipo de coda remetem apenas a uma proposta de escrita das crianças (proposta 3), a saber, a cantiga infantil

Pirulito que bate, bate

Pirulito que já bateu

Quem gosta de mim é ela

Quem gosta dela sou eu

Tivemos um total de 9 registros de coda semivocálica posterior, de sete diferentes sujeitos, distribuídas da seguinte maneira: $b a t e u=4 ; e u=5$.

Mais uma vez, em consonância com aspectos observados em ocorrências de coda vibrante, também as duas palavras encontram-se em posição de rima - fato que, como vimos, remete a contribuições do gênero discursivo, do ritmo e do acento para o estabelecimento de vínculos entre características fonéticosegmentais e características ortográficas na escrita infantil.

Também mais uma vez - desta feita, em consonância com aspectos observados não só em ocorrências de coda vibrante, como ainda em ocorrências de coda fricativa - a informação morfológica pode ter contribuído para esse estabelecimento de vínculos. Com efeito, em uma das possibilidades (bateu), a coda semivocálica posterior coincide com uma marca morfológica - a de sufixo número-pessoal (CAMARA Jr., 1971, p. 69).

Mas outro tipo de característica da linguagem pode ter favorecido o vínculo entre características fonético-segmentais e características ortográficas na coda semivocálica posterior: o próprio fato de ela constar da palavra que indicia o sujeito da enunciação. Reforça essa interpretação o fato de, das 5 ocorrências em que ela se fez presente, 4 delas serem marcadas de acordo com as convenções ortográficas, ou seja, com "u".

O único registro desse tipo de coda que foge às convenções, a saber, $e o$, abre a possibilidade para outros tipos de consideração. Ao relacionarmos as 
marcas aos sujeitos que concretamente as produziram, vimos tratar-se, nesse caso, de um sujeito do sexo masculino. Desse modo, a grafia com $o$, além de indiciar uma característica enunciativa da linguagem, a de mostrar o sujeito da enunciação, ainda pode indiciar um provável reconhecimento, por parte do sujeito, de que a terminação "o" em muitas palavras da língua indica o gênero masculino". Ou seja, esse sujeito escrevente faz uma transposição do morfema de gênero masculino para outros tipos de palavras nas quais ele não ocorreria - como é o caso do pronome pessoal que indica o sujeito da enunciação. Desse modo, teríamos no registro eo um entrecruzamento de características que favoreceriam os vínculos entre o fonético-segmental e o ortográfico na escrita desse sujeito: características enunciativas e características morfológicas.

\section{Considerações finais}

Os resultados permitem detectar que são complexos os fatos que contribuem para o registro da coda silábica na escrita infantil, complexidade que, a nosso ver, coloca em questão uma vinculação supostamente direta entre características fonético-segmentais da fala e características ortográficas nesse tipo de escrita.

Essa complexidade parece resultar do fato de que o sujeito, ao iniciar o seu contato formal com a escrita, além de, naturalmente, estabelecer relações entre informações que traz de sua inserção em práticas de oralidade e em práticas de letramento (desenvolvidas dentro e fora do contexto escolar), vê-se às voltas também com múltiplas possibilidades de inter-relação entre diferentes aspectos da língua e da linguagem, indícios das quais podem ser detectados ortograficamente em sua escrita. Desse modo, o olhar que freqüentemente estabelece vínculos diretos entre características fonético-segmentais possíveis em enunciados falados e características ortográficas é o mesmo olhar que deixa passar despercebidos entrecruzamentos de vários desses múltiplos aspectos da língua e da linguagem na escrita da criança. Em outras palavras, é o olhar pouco atento aos movimentos tão característicos das relações entre o sujeito escrevente e a linguagem que se pode detectar em sua produção escrita inicial.

Talvez essa complexidade no registro das codas se deva ainda ao fato de que, embora a integração entre aspectos múltiplos da língua e da linguagem se mostre de algum modo para a criança, a ela também se faz mostrar a fluidez e, 
logo, as possibilidades de deslocamento no estabelecimento de relações isomórficas entre esses aspectos - em nosso caso, fonéticos (segmentais e prosódicos), morfológicos, enunciativos, discursivos e ortográficos. É a própria linguagem, enfim, que se mostra como não transparente à criança.

De algum modo, no entanto, mesmo movimentando-se nessa fluidez, a criança, entre idas e vindas, tende a integrar esses diferentes aspectos em sua escrita, estando essa escrita em acordo, ou não, com as convenções ortográficas. Até onde nossos resultados permitem fazer conjecturas - e, dentre eles, destaquemos o aumento de registros de coda (de qualquer tipo) ao longo do ano -, a inserção da criança em práticas de letramento, sobretudo aquelas mais diretamente voltadas para a alfabetização, parece ser o fator mais determinante para o êxito dessa integração por parte das crianças.

\section{Notas}

${ }^{1}$ Uma descrição das características da sílaba no Português Brasileiro é encontrada, por exemplo, em Collischonn (1996) e em Bisol (1999).

${ }^{2}$ Não é consensual, nos estudos fonológicos sobre a nasalidade do português, a atribuição do estatuto de coda para o que Camara Jr. (1975) classifica como arquifonema nasal. Uma discussão sobre as diferentes tendências de interpretação para esse fenômeno pode ser vista, por exemplo, em Miranda (2008b). Como está absolutamente fora de nossos propósitos, neste trabalho, uma discussão sobre a nasalidade no português, adotaremos, aqui, a interpretação que dela é feita por Bisol (1999), seguindo a tradição de Camara Jr. A principal razão para essa adoção é a de que, na escrita, independentemente de como é interpretada nos estudos fonológicos, a nasalidade é ortograficamente marcada por grafemas numa mesma sílaba (como, por exemplo, em "caMpo" ou em "caNto").

${ }^{3}$ Sobre esses tipos de ditongos, cf. Bisol (1989).

${ }^{4}$ Segue-se o texto completo: Motorista, motorista, como é bom andar pelas ruas com muita atenção.

${ }^{5}$ Cf., a propósito, Massini-Cagliari (1992) e Gama-Rossi (1999).

${ }^{6}$ Como nossos dados são extraídos de textos produzidos em contexto escolar, o 'gênero masculino' será aqui entendido como sendo marcado, por default, com 'o', já que é dessa maneira que essa informação é difundida na escola. 


\section{Referências Bibliográficas}

BISOL, L. O ditongo na perspectiva da fonologia atual. D.E.L.T.A, v. 5, n. 2, p. 185-224, 1989.

BISOL, L. A sílaba e seus constituintes. In: NEVES, M.H.M. (Org.). Gramática do português falado (v. VII). São Paulo: Humanitas / Campinas: Editora da Unicamp, 1999. p. 701-741.

CAMARA Jr., J. M. A análise da flexão verbal. In: Problemas de lingüística descritiva. 7. ed. Petrópolis: Vozes, 1971. p. 65-71.

CAMARA Jr., J. M. Problemas de lingüística descritiva. 7. ed. Petrópolis: Vozes, 1975.

CHACON, Lourenço. Ocorrências de coda silábica simples na escrita infantil. Anais do VII Encontro do Círculo de Estudos Lingüísticos do Sul. Pelotas: UCPel, 2008 (a sair).

COLLISCHON, G. A sílaba em português. In: BISOL, L. Introdução a estudos de fonologia do português brasileiro. Porto Alegre: EDIPUCRS, 1996.

GAMA-ROSSI, A. J. Relações entre desenvolvimento lingüístico e neuromotor: a aquisição da duração do português brasileiro. 1999. Tese (Doutorado em Lingüística) - Instituto de Estudos da Linguagem, Universidade Estadual de Campinas.

MASSINI-CAGLIARI, G. Acento e ritmo. São Paulo: Contexto, 1992.

MIRANDA, A. R. M. A aquisição ortográfica das vogais do português - relações com a fonologia e a morfologia. Revista Letras (Programa de Pós-Graduação em Letras da UFSM), n. 36, 2008a (a sair).

MIRANDA, A. R. M. Aspectos da escrita espontânea e da sua relação com o conhecimento fonológico. In: LAMPRECHT, R. R. Aquisição da Linguagem: estudos recentes no Brasil. Porto Alegre: EDIPUCRS, 2008b. (a sair).

NESPOR, M.; VOGEL, I. Prosodic phonology. Dordrechet: Foris Publications, 1986.

SELKIRK, E. The syllable. In: HULST, F.V.; SMITH, N. (Org.). The structure of phonological representations (Part II). Dordrecht: Foris, 1982. 